\title{
PPGLinC \\ Programa de Pós-Graduação

\section{"É POUCO ['pok], MAS É MEU”: ANÁLISE COMPARATIVA DO APAGAMENTO DAS VOGAIS ALTAS FINAIS EM LOCALIDADES DA BAHIA E DE MINAS GERAIS}

\begin{abstract}
"É POUCO ['pok] MAS É MEU": COMPARATIVE ANALYSIS OF THE DELETION OF HIGH FINAL VOWELS IN LOCATIONS IN BAHIA AND MINAS GERAIS
\end{abstract}

\author{
Maria do Carmo Sá Teles de Araújo Rolo ${ }^{1}$ \\ Secretaria de Educação do Estado da Bahia
}

Jacyra Andrade Mota ${ }^{2}$ Universidade Federal da Bahia

Resumo: Este trabalho visa confrontar o apagamento das vogais altas finais [I] e [v], na comunidade rural de Beco (ROLO, 2010), com os resultados de quatro localidades: Bom Jesus da Lapa e Macaúbas, na Bahia; e Almenara e Itaobim, em Minas Gerais (ROLO, 2016). Para esta análise, assumem-se os postulados da Sociolinguística Variacionista (LABOV, 2008 [1972]), bem como os pressupostos da Dialetologia Pluridimensional. A amostra compõe-se de 40 inquéritos realizados pelo próprio pesquisador. Como variáveis linguísticas, consideram-se a consoante prévocálica e contexto fonético seguinte. Como variáveis extralinguísticas, consideram-se sexo, faixa etária, tipo de questionário e localidade. O confronto de dados mostra que, em Beco, realiza-se majoritariamente mais apagamento, tanto para [v] quanto para [I]. Itaobim, em Minas Gerais, apresenta a mesma tendência de apagamento observada em Beco.

Palavras-Chave: Apagamento de vogais; Diatopia; Variação fônica; Vogais átonas finais.

1 mcstar.rolo@gmail.com

2 jacymota@gmail.com 
Abstract: This work aims to confront the deletion of the final high vowels $[I]$ and $[v]$, in the rural community of Beco, analized in Rolo (2010), with the results of the four locations: Bom Jesus da Lapa and Macaúbas, in Bahia; and Almenara and Itaobim, in Minas Gerais (ROLO, 2016). For this analysis, the postulates of Variationist Sociolinguistics (LABOV, 2008 [1972]) are assumed, as well as the assumptions of Multi-dimensional Dialectology. The sample consists of 40 inquiries realized by the own researcher. The pre-vocalic consonant and the following phonetic context were considered as linguistic variables. The extralinguistic variables we are considered relate to the sex, age, type of questionnaire and locality. The comparison of data shows that, in Beco, most deletion takes place, both for [v] and [I]. Itaobim, in Minas Gerais, presents the same tendency of deletion observed in Beco.

Keywords: Deletion of vowels; Diatopia; Phonic variation; Final unstressed vowels.

\section{INTRODUÇÃO}

O apagamento de vogais átonas em final de vocábulos é uma alteração fônica que se caracteriza como um processo fonético-fonológico importante na história da língua. Esse fenômeno foi observado desde a passagem do latim para o português, em supressões que ocorreram em final de palavras, como se pode ver em amare do latim para amar do português. O fato também é atestado no português arcaico, por exemplo, em Nunes ([1919] 1951), quando registrou a forma apocopada $e l$ na fala popular:

O latim vulgar empregou de preferência no masculino ille, que se acha representado em português por ele e $e l$, que divergem entre si apenas em o primeiro conservar o $e$ final, que no segundo, ainda em uso no povo, que lhe dá para o plural eis, caiu. (NUNES, [1919] 1951, p. 235)

A língua continua evoluindo e os processos de apagamento continuam fazendo parte dessa transformação, como revelam as pesquisas geolinguísticas, inclusive as publicadas nos atlas linguísticos no Brasil e em Portugal. O apagamento em foco, no presente estudo, ocorre em sílaba átona postônica final de palavras paroxítonas, especificamente com as vogais finais [I] e [U], como se 
observam nos exemplos “É pouco ['рок], mas é meu 3" (Beco, homem, f. etária 2) e "Eu planto é verdura, é alface [aw'fas]" (Beco, homem, f. etária 2).

O estudo aqui proposto pretende confrontar, à luz da Dialetologia Pluridimensional e da Sociolinguística Variacionista (LABOV, [1972] 2008), os resultados da análise variacionista na localidade rural de Beco (ROLO, 2010), que documentou a existência do fenômeno em grandes proporções, com os resultados da análise das quatro localidades que integram a tese de doutorado: Bom Jesus da Lapa e Macaúbas, na Bahia; e Almenara e Itaobim, em Minas Gerais (ROLO, 2016). Esse confronto tem o propósito de observar o ambiente linguístico e extralinguístico em que ocorrem as variáveis, examinando semelhanças e diferenças em relação à aplicação da regra de apagamento para as vogais átonas [I] e [U] em finais de vocábulos.

As localidades da Bahia e de Minas Gerais foram escolhidas por serem rotas das tropas na época do Garimpo, por estarem inseridas nos veios diamantíferos por onde circulavam as riquezas naturais, por estarem em sintonia com os currais de gado que atravessavam os sertões da Bahia rumo aos gerais, compartilhando, portanto, a mesma história impregnada de passagens ligadas à exploração de riquezas, ao povoamento do território por colonizadores portugueses e à propagação da língua.

Por se tratar de áreas em que algumas pesquisas e os próprios atlas linguísticos regionais - Esboço de Atlas Lingüístico de Minas Gerais (RIBEIRO et al., 1977) e Atlas Prévio dos Falares Baianos (ROSSI, 1963) - assinalam casos de redução e apagamento da vogal átona final, espera-se que o estudo comparativo desses registros possa ajudar na compreensão e descrição das tendências atuais de fala nas localidades.

3 Neste estudo, as palavras com presença ou ausência das vogais átonas finais [I] e [ひ] serão transcritas foneticamente. 
Sabe-se que o quadro das vogais átonas finais no português do Brasil apresenta-se bastante instável com enfraquecimento, redução ou queda do número de fonemas. De acordo com a descrição de Câmara Jr. ([1953] 2008), o que caracteriza esse quadro é a redução do número de fonemas. Isto é, mais de uma oposição desaparece ou se suprime, ficando para cada uma um fonema em vez de dois. É o que se convencionou a chamar de neutralização, como em povo ['povu], aquele [a'keli]. Nas comunidades investigadas, como na maioria das áreas brasileiras, prevalece a pronúncia do [I] átono em vez de [e] e do [u] átono em vez de [o] em posição final de vocábulos.

Câmara Jr. ([1953] 2008) ressalta que os sons vocálicos classificados como surdos ou reduzidos são consequência da posição átona da vogal. Nessa posição, o autor afirma que "as sílabas finais átonas são as mais débeis, em vocábulos de acento tônico na penúltima sílaba, ditos paroxítonos" (CÂMARA JR., [1953] 2008, p. 47). Essa debilidade máxima da sílaba átona final provoca o seu enfraquecimento, a sua redução e até a sua queda em decorrência da variação dialetal. Nas comunidades baianas e mineiras, observa-se uma forte tendência ao desaparecimento da vogal átona em final de palavras paroxítonas.

O presente estudo tenciona responder aos questionamentos que nortearam a pesquisa e será pautado em algumas hipóteses: i. O desaparecimento do segmento fonético átono no final das palavras é um fato linguístico marcante na caracterização das localidades. ii. Há influência de fatores externos tais como: povoamento, tipo de questionário, faixa etária e sexo dos informantes. iii. Há fatores linguísticos internos, como as consoantes pré-vocálicas em sílaba final que favorecem o apagamento. iv. Esse apagamento estaria relacionado ao que se observa ao sul de Portugal e nos Açores.

Este trabalho é constituído de um breve panorama do apagamento das vogais altas átonas finais no português do Brasil, seguido da metodologia que especifica os procedimentos adotados para a investigação científica, bem como 
da caracterização acústica da variável e a análise comparativa dos dados que é intercalada por gráficos onde será visualizado o tratamento estatístico aplicado. Por fim, os resultados serão apresentados de forma resumida.

\section{PANORAMA DO APAGAMENTO DAS VOGAIS ALTAS ÁTONAS FINAIS NO PORTUGUÊS DO BRASIL}

O apagamento de vogais em sílaba final de palavras está presente no português do Brasil, não como um fenômeno generalizado, mas como um processo que caracteriza a fala de informantes em algumas áreas do país, conforme mostram pesquisas como Oliveira $(2006,2012)$, Rolo $(2010,2016)$ e os atlas linguísticos publicados (RIBEIRO et al., 1977), (ROSSI, 1963), (FERREIRA et al., 1987) e (BESSA, 2010).

Em gramáticas do português brasileiro, já se encontram registros do apagamento de vogais átonas finais, como se observa em Perini (2010), quando inclui a omissão das vogais [e] e [o] em final de sílaba átona. Em relação à omissão da vogal [e], o autor faz a seguinte consideração:

$\mathrm{O} e$ final átono, como sabemos, se pronuncia normalmente [I]. No entanto, quando a consoante precedente é uma fricativa ou africada palatal - ou seja, $\left[\mathrm{t} \int, \int, \mathrm{d}_{3}, 3\right]-\mathrm{o}[\mathrm{I}]$ às vezes não se ouve, de modo que a palavra termina, foneticamente, em consoante. Por exemplo, ponte ['põt $\left.\int\right]$, mexe ['mef], rende ['rẽd3], hoje ['o3]. (PERINI, 2010, p. 348)

Em relação à omissão de [o] final, Perini (2010) explica que este é muito reduzido em certos ambientes e que, em final de enunciados, é frequentemente omitido:

$\mathrm{O}[\mathrm{u}$ ] átono final, grafado $o$, se pronuncia muito reduzido em certos ambientes. Em final de enunciado, isto é, antes de silêncio ou pausa, ele é frequentemente omitido. Dessa forma, uma frase como eu vi um gato muitas vezes se pronuncia como [ew'viứgat] sem vogal final. (PERINI, 2010, p. 349) 
O fenômeno do apagamento de vogais finais já se encontra registrado também em território português. Cunha e Cintra ([1984] 2013, p. 29), na Nova Gramática do Português Contemporâneo, mencionam o fenômeno do apagamento numa extensa área da Beira Baixa, Alto Alentejo e no ocidente do Algarve. Os autores também se referem, dentre outros traços mais salientes, à "queda da vogal átona final grafada -o ou sua redução ao som [ə], por exemplo: cop (ə), cop (ə)s, por copo, copos; tüd (ə) por tudo".

Apesar de não ter sido o foco principal em nenhum dos estudos consultados, o apagamento das vogais finais [I] e [ $]$, encontra-se documentado em Portugal, tanto no continente (SEGURA DA CRUZ, 1987; NAVARRO, 1962; VITORINO, 1987), quanto nos Açores (MEDEIROS, 1964; BERNARDO, 2003; FERREIRA et al., 2001.), incluindo pesquisas e atlas linguísticos.

\section{ASPECTOS TEÓRICO-METODOLÓGICOS}

Para realização desta pesquisa, recorreu-se aos pressupostos teóricometodológicos da Sociolinguística Variacionista, segundo a qual a variação não é aleatória, é uma propriedade inerente e regular do próprio sistema linguístico e os dados coletados podem ser submetidos à análise quantitativa. Do mesmo modo lançou-se mão da Dialetologia Pluridimensional que tem se ocupado do estudo linguístico no que se refere ao espaço, considerando também os aspectos de ordem social.

A abordagem sociolinguística concentra-se na língua em uso dentro da comunidade de fala, como enfatiza Labov ([1972] 2008, p. 21) “Não se pode entender o desenvolvimento de uma mudança linguística sem levar em conta a vida social da comunidade em que ela ocorre". Sob essa perspectiva, a Sociolinguística tem como base a investigação dos fenômenos linguísticos em seu 
contexto social, analisando-os sistematicamente, através de um sistema heterogêneo constituído por regras variáveis.

Na pesquisa dialetal, com o advento da Geolinguística Pluridimensional, são abarcados aspectos sociolinguísticos que recobrem questões que acrescentam ao parâmetro diatópico a variação social do uso da língua. Esse enfoque dialetal e sociolinguístico tem influenciado os rumos atuais da Dialetologia, ampliando de forma significativa os estudos dialetais, com base nas relações que surgem entre língua e características sociais. Sob esse panorama, busca-se entender o processo de variação presente nas comunidades selecionadas para este estudo, conduzindo a uma maior compreensão dessa realidade.

Este trabalho parte dos dados linguísticos de comunidades de fala localizadas na Bahia e em Minas Gerais, de características e composições diversas, com vistas a estabelecer um confronto entre as localidades para observar diferenças na fala.

O estudo aqui apresentado foi feito com uma amostra constituída de 40 inquéritos, sendo oito analisados na dissertação de mestrado (ROLO, 2010) e 32 da tese de doutorado (ROLO, 2016). Os dados que compõem a amostra foram obtidos em inquéritos linguísticos realizados in loco, através de um questionário fonético-fonológico (QFF) com 115 perguntas e de conversa livre sobre temas de interesse do informante, que se identifica como "discurso semidirigido", organizados especificamente para este fim. Esses questionários tiveram como eixo norteador os temas, propostos pelo questionário do ALiB (COMITÊ NACIONAL DO PROJETO ALiB, 2001).

A amostra analisada pauta-se em elocuções de falantes nativos das diferentes áreas contempladas na Bahia (a localidade rural de Beco, Bom Jesus da Lapa e Macaúbas) e em Minas Gerais (Almenara e Itaobim). Os informantes possuem até o ensino fundamental II incompleto e foram estratificados em duas 
faixas etárias: faixa 1 (18 a 30 anos), faixa 2 (50 a 65 anos). Quanto ao sexo dos informantes, consideraram-se homens e mulheres.

Como dizem os parâmetros postulados por Labov ([1972] 2008), toda variação linguística é condicionada por fatores estruturais e/ou por fatores sociais ou externos. Se não é o contexto linguístico que determina o emprego de uma das formas, parece que sempre se interpõem fatores externos para decidir qual forma irá ocorrer numa dada situação de fala.

Assim, para esta análise, foram considerados dois fatores de natureza linguístico-estrutural: a consoante pré-vocálica, com o intuito de verificar o tipo de consoante que mais favorece o apagamento, e o contexto fonético seguinte, em função da necessidade de observar se o contexto seguido de consoante ou pausa poderia afetar a realização das variantes.

As variáveis discursivas controladas incluem dois tipos de questionários: o questionário fonético-fonológico (QFF) e um questionário tipo discurso semidirigido no qual, através de quatro temas apresentados ao informante, se observam elocuções mais espontâneas.

Os dados foram submetidos ao programa Goldvarb 2001 (ROBINSON; LAWRENCE; TAGLIAMONTE, 2001) que gera pesos relativos ${ }^{4}$ com que cada fator linguístico e extralinguístico está correlacionado ao uso de uma variante. Além disso, utilizou-se o programa acústico PRAAT $^{5}$ para a caracterização acústica da variável (presença vs. ausência da vogal final) através da apresentação de espectrogramas.

Este estudo adotou como base para a comparação os resultados encontrados no povoado do Beco, localidade rural que faz parte do município de Seabra-BA, uma das Microrregiões da Chapada Diamantina e está situada à margem da BR 242, a $470 \mathrm{KM}$ de Salvador. Os dados levantados nessa

4 O peso relativo resulta de uma análise multivariada e pode ser: neutro $(0,50)$, favorecedor (acima de 0,50) e desfavorecedor (abaixo de 0,50). (Cf. GUY; ZILLES, 2007).

5 PRAAT $5.0<$ www.praat.org>. Acesso em: 13 de jan. 2010. 
comunidade mostram que há um distanciamento entre o português padrão e o português não-padrão com relação ao apagamento dos segmentos fonéticos átonos $[\mathrm{I}]$ e $[\mathrm{U}]$ na sílaba final das palavras paroxítonas, como se observam nos exemplos 1 e 2:

(1) “Passar um bife ['bif]” (Beco, homem, f. etária 2)

(2) “Tudo ['tud] lá de trás escondido [iskõ'did], né”? (Beco, homem, f. etária 2).

Essas variações são fenômenos fortemente marcados entre os falantes de Beco e são também fatores que os identificam como pertencentes a tal comunidade que é estigmatizada linguística e socialmente.

\section{CARACTERIZAÇÃO ACÚSTICA DA VARIÁVEL}

O apagamento das vogais átonas finais [I] e [U] na realização da fala, verificado com grande intensidade na localidade do Beco, será visualizado nos espectrogramas que mostram a presença e a ausência do segmento vocálico em final de palavras. Para isso, serão analisadas as ocorrências das variantes nos itens bife e prefeito, obtidos por meio de entrevistas.

As figuras 1 e 2 apresentam os espectrogramas da palavra bife na localidade rural do Beco. Pode-se, então, caracterizar acusticamente o fenômeno variável em estudo na cadeia de fala da seguinte maneira: 
Figura 1: Formas de onda, espectrograma (com sobreposição dos formantes e curva de F0) e camada de etiquetagem da palavra bife ['bifI] - (Beco, mulher, f. etária 1)

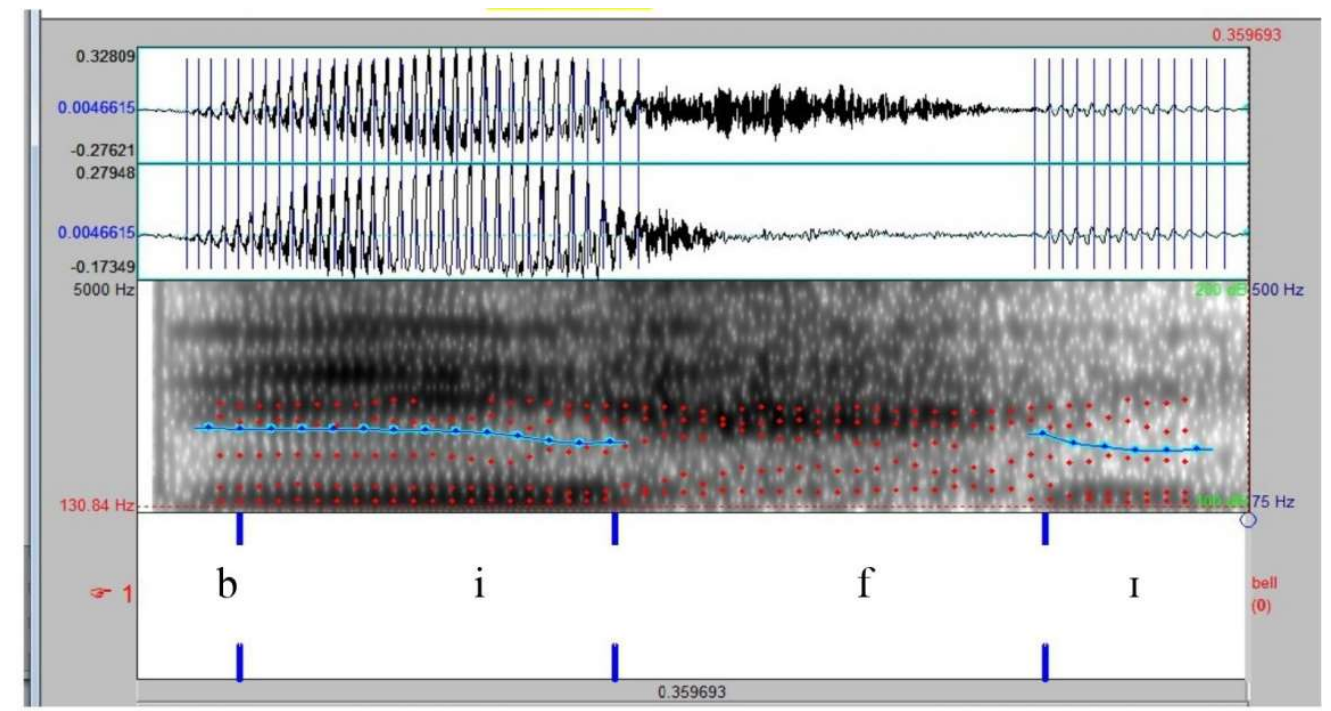

Fonte: Rolo (2010)

Figura 2: Formas de onda, espectrograma (com sobreposição dos formantes, curva de F0 e curva da amplitude) e camada de etiquetagem da palavra bife ['bif] (Beco, mulher, f. etária 2)

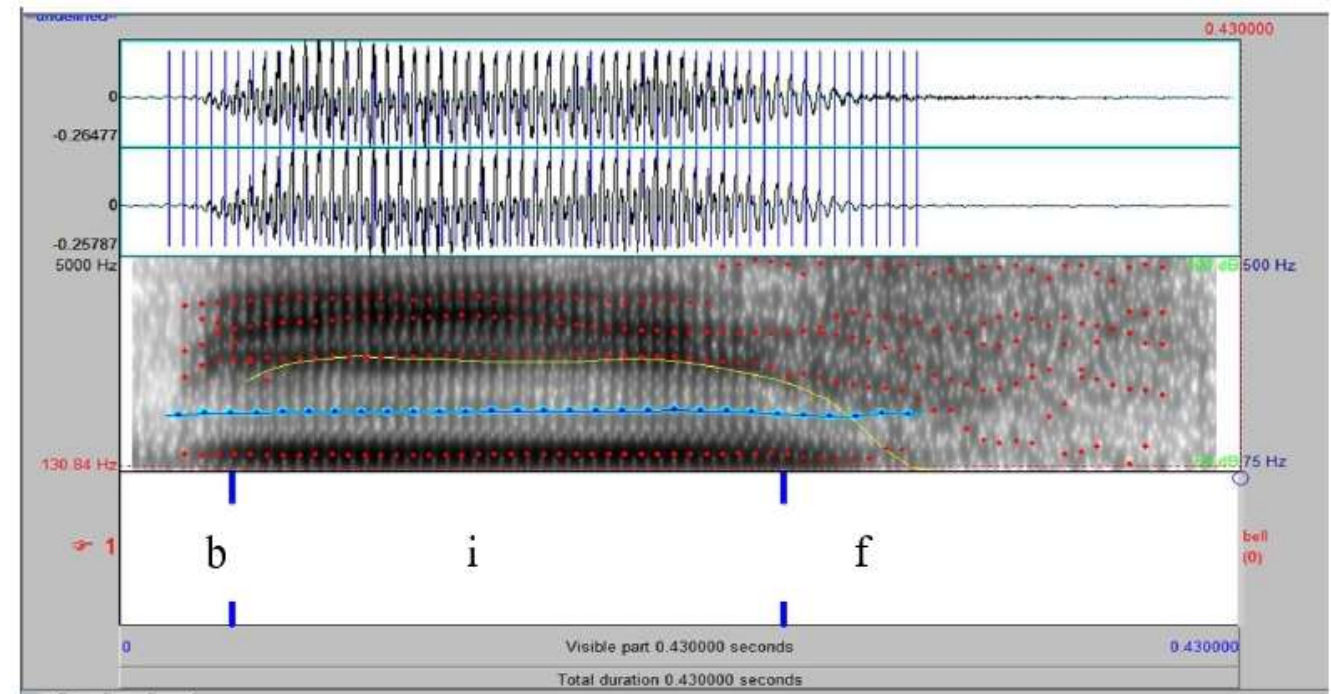

Fonte: Rolo (2010).

Na Fig. 1, para a realização da palavra bife ['bifi], o sinal acústico mostra claramente a presença de formantes para a vogal final [I] com frequências que variam em torno de F1=333 Hz e F2=1907 Hz, o que significa a realização da vogal [I] pelo falante. Sabe-se que cada vogal apresenta características acústicas e 
articulatórias específicas. Com um F1 baixo e F2 mais alto, visualiza-se o registro físico da vogal alta [I]. Já na Fig. 2, é possível observar nitidamente que não há configuração formântica de uma vogal final para realização de bife ['bif]. Em termos acústicos, no espectrograma, visualiza-se o ruído decorrente da fricção do ar passando pela estreita passagem do trato vocal. Observa-se, ainda, um alongamento da vogal da sílaba anterior à qual a consoante fricativa fica presa, como se pode ver no registro físico dessa consoante na imagem espectrográfica.

Figura 3: Formas de onda, espectrograma (com sobreposição dos formantes e curva de F0) e camada de etiquetagem da palavra prefeito [pre'fejto] (Beco, homem, f. etária 1)

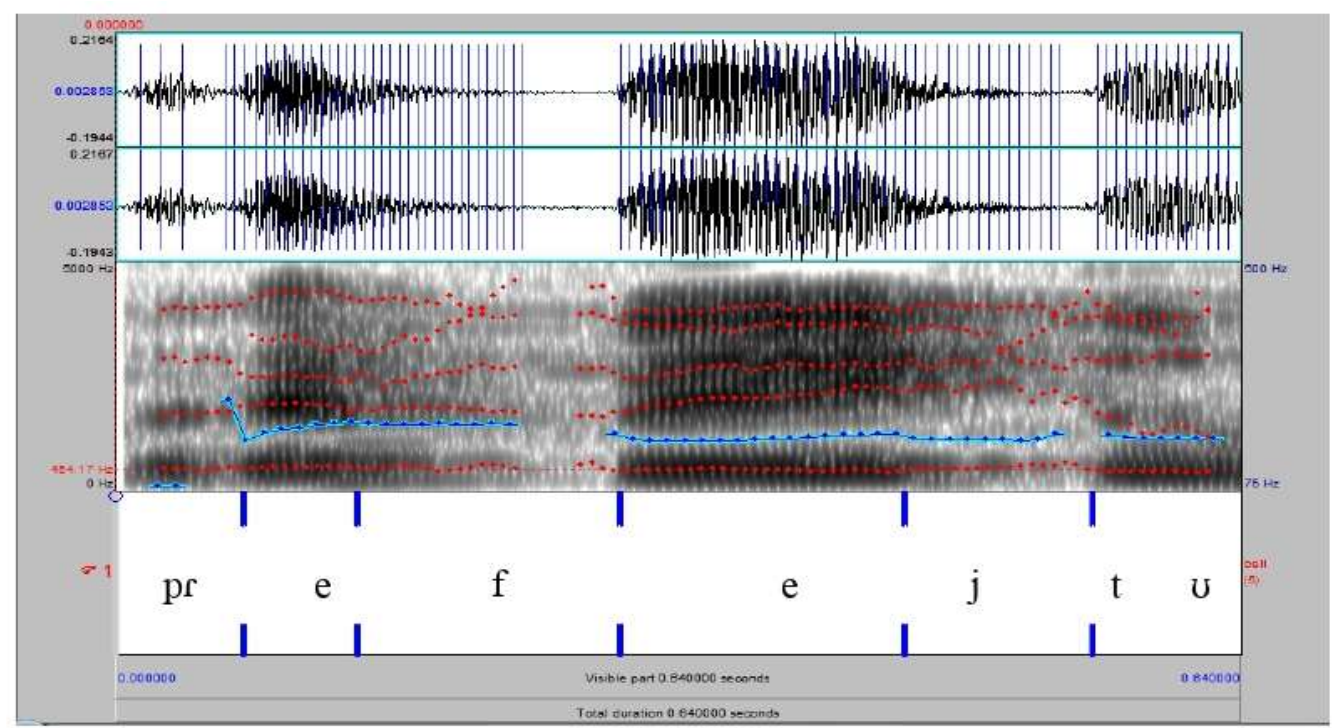

Fonte: Rolo (2010) 
Figura 4: Formas de onda, espectrograma (com sobreposição dos formantes, curva de F0 e curva da amplitude) e camada de etiquetagem da palavra prefeito [pre'fet] (Beco, mulher, f. etária 2)

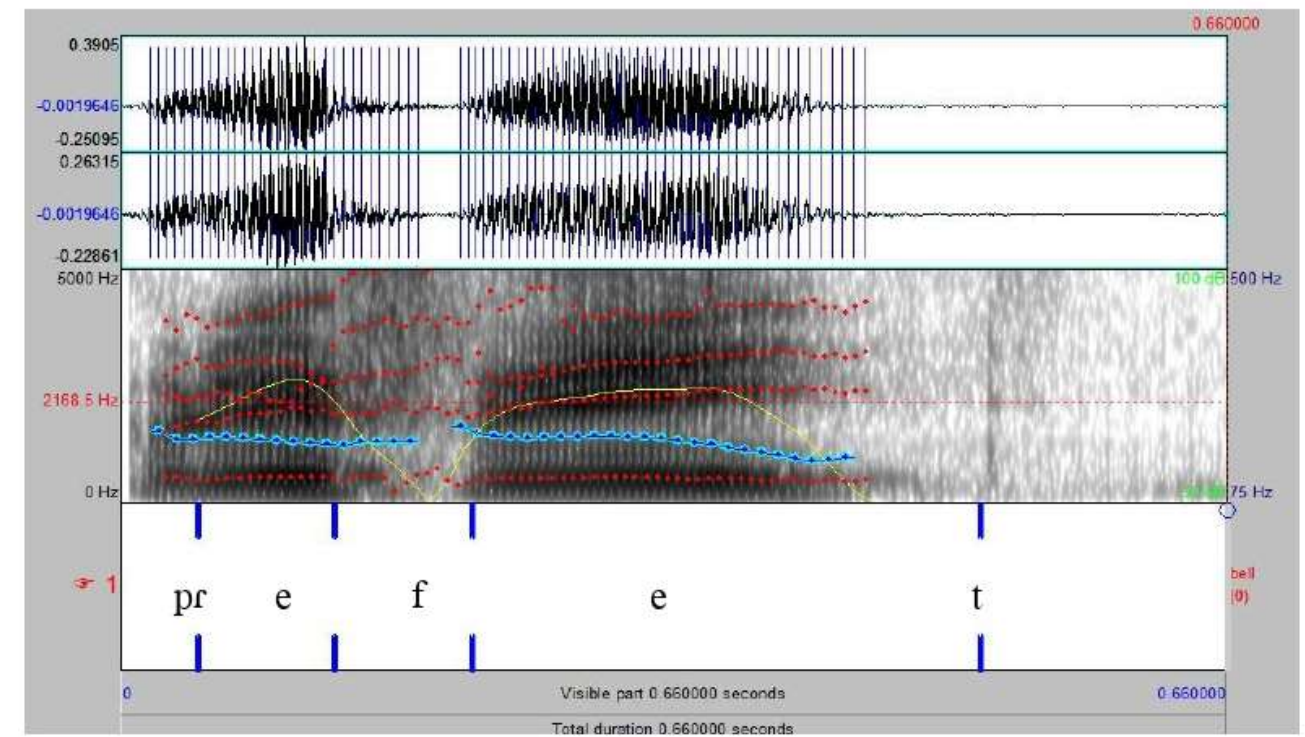

Fonte: Rolo (2010)

Na Fig. 3, para a realização de prefeito [pre'fejtu], o sinal acústico mostra com clareza a presença da vogal final [u]. Os formantes para esse segmento vocálico final apresentam frequências que variam em torno de F1=412 Hz e F2=1312 Hz. Com um F2 menor, se comparado à vogal [I], é possível visualizar o registro físico da vogal alta [u]. Já na Fig. 4, verifica-se que não há vestígio acústico algum que possa levar a uma configuração formântica de uma vogal final na realização do vocábulo prefeito produzido como [pre'fet], há apenas uma simples explosão da consoante oclusiva [t], seguida de silêncio. Além disso, é possível visualizar um alongamento da vogal da sílaba anterior, provavelmente uma compensação pela queda da vogal final.

\section{AS ANÁLISES DOS DADOS: POVOADO DE BECO VERSUS CIDADES DA BAHIA E DE MINAS GERAIS}

Em Beco, das 1.744 ocorrências quantificadas para a vogal [u], 1.311 foram realizadas na forma não-padrão, correspondendo a um percentual de $75 \%$ de 
ausência da vogal final átona [u]. Das 793 ocorrências quantificadas para a vogal [I], 651 foram realizadas na forma não-padrão, correspondendo a um percentual de $82 \%$ de ausência da vogal final átona [I]. Enquanto que, nas localidades da Bahia e de Minas Gerais reunidas, foram quantificadas 5.288 ocorrências para a vogal [u], das quais 2.023 foram de apagamento da vogal, correspondendo a um percentual de 38\%; quanto à vogal [I], foram quantificadas 1.613 ocorrências, das quais 756 foram de apagamento, correspondendo a um percentual de $46 \%$. Ressalta-se que, em Beco, realizam-se, majoritariamente, mais apagamentos do que nas outras localidades reunidas. Os dados mostram que o apagamento nessa localidade é característica local e pode estar associado às questões do povoamento e do isolamento da localidade.

\subsection{A consoante pré-vocálica}

Em Beco, Rolo (2010) tomou para análise as consoantes pré-vocálicas individualmente e constatou que o apagamento da vogal [u] é favorecido pelas consoantes [p, s, n, $\left.\int, \mathrm{v}, \mathrm{d}, \mathrm{f}\right]$ e da vogal [I], pelas consoantes [t, l]. Nas outras localidades (Bom Jesus da Lapa, Macaúbas, Almenara e Itaobim), destaca-se o predomínio das consoantes fricativas e nasais para a vogal [u] e das consoantes oclusivas e laterais para a vogal [I]. Na ordem decrescente de valores, observamse: 
Tabela 1: Apagamento da vogal átona final [ช] e [I], em função da consoante prévocálica: Beco versus localidades baianas e mineiras (em peso relativo)

\begin{tabular}{|c|c|c|c|c|}
\hline Localidades & Vogal [u] & & Vogal [I] & \\
\hline \multirow{8}{*}{ Beco } & $\begin{array}{l}\text { Oclusiva bilabial surda } \\
\text { [p] }\end{array}$ & 0,64 & $\begin{array}{l}\text { Oclusiva dento- } \\
\text { alveolar surda }[\mathrm{t}]\end{array}$ & 0,73 \\
\hline & $\begin{array}{l}\text { Fricativa dento- } \\
\text { alveolar surda [s] }\end{array}$ & 0,63 & $\begin{array}{l}\text { Lateral alveolar } \\
\text { sonora [l] }\end{array}$ & 0,63 \\
\hline & $\begin{array}{l}\text { Nasal dento-alveolar } \\
\text { sonora [n] }\end{array}$ & 0,61 & & \\
\hline & $\begin{array}{l}\text { Fricativa alveopalatal } \\
\text { surda }\left[\int\right]\end{array}$ & 0,61 & & \\
\hline & $\begin{array}{l}\text { Fricativa labiodental } \\
{[\mathrm{v}]}\end{array}$ & 0,61 & & \\
\hline & $\begin{array}{l}\text { Oclusiva dento- } \\
\text { alveolar sonora [d] }\end{array}$ & 0,54 & & \\
\hline & $\begin{array}{l}\text { Fricativa labiodental } \\
\text { surda [f] }\end{array}$ & 0,53 & & \\
\hline & $\begin{array}{l}\text { Fricativa alveopalatal } \\
\text { sonora [3] }\end{array}$ & 0,51 & & \\
\hline \multirow{2}{*}{$\begin{array}{c}\text { Localidades } \\
\text { baianas e } \\
\text { mineiras }\end{array}$} & Fricativas & 0,60 & Oclusivas & 0,74 \\
\hline & Nasais & 0,57 & Laterais & 0,69 \\
\hline
\end{tabular}

Fonte: Rolo (2010, p. 163, 199; 2016, p. 256, 230), com adaptações.

$\mathrm{Na}$ análise conjunta das localidades da Bahia (Bom Jesus da Lapa e Macaúbas) e de Minas Gerais (Almenara e Itaobim), as consoantes foram agrupadas quanto ao modo articulação. Os resultados obtidos para este agrupamento de consoantes mostraram que a vogal [u] é mais apagada quando vem antecedida pelas consoantes fricativas $(0,60)$ e nasais $(0,57)$, enquanto a vogal [I] é mais apagada em contextos antecedidos pelas consoantes oclusivas $(0,74)$ e laterais $(0,69)$, como se pode observar na Tabela 1.

À propósito de explicações possíveis para esse fenômeno, o que se pode apresentar no momento são apenas algumas hipóteses. Se, do ponto de vista 
histórico, encontram-se, desde o latim, casos de apócope da vogal anterior precedida de líquidas e fricativas não labiais que passam a formar sílaba com a vogal anterior da consoante precedente, como se observa em sale $\sim$ sal; male $\sim$ mal, mare $\sim$ mal, vice $\sim$ vez, chama a atenção, no caso das áreas analisadas, a ocorrência da apócope também em outros contextos (oclusivas e fricativas labiais), contrariando afirmações como as de Câmara Jr. (2004, p. 52) "as únicas consoantes pós-vocálicas possíveis são as líquidas e as fricativas não labiais". Nesse sentido, o fato mais marcante foi observado em Minas Gerais, onde o fenômeno é muito frequente (CORRÊA, 1998; OLIVEIRA, 2006; 2012).

\subsection{O contexto fonético seguinte}

No que concerne ao contexto fonético seguinte, em Beco, o contexto seguido de consoante está mais propenso ao apagamento tanto da vogal [u], com 0,55 de peso relativo, quanto da vogal [I] com 0,58. Nas localidades da Bahia (Bom Jesus da Lapa e Macaúbas) e de Minas Gerais (Itaobim e Almenara), esse contexto também favorece com maior força o apagamento, com 0,61 de peso relativo para [U] e 0,58 para [I], como se pode ver na Tabela 2:

Tabela 2: Apagamento das vogais átonas finais [U] e [I], em função do contexto fonético seguinte: Beco versus localidades baianas e mineiras (em peso relativo)

\begin{tabular}{lcccc}
\hline \multicolumn{1}{c}{ Localidades } & \multicolumn{2}{c}{ Vogal [u] } & \multicolumn{2}{c}{ Vogal [I] } \\
\hline & Consoante & Pausa & Consoante & Pausa \\
\cline { 2 - 5 } $\begin{array}{l}\text { Beco } \\
\text { Localidades } \\
\text { baianas e mineiras }\end{array}$ & 0,55 & 0,43 & 0,58 & 0,27 \\
\hline
\end{tabular}

Fonte: Rolo (2010, p. 166, 201; 2016, p. 233, 261), com adaptações.

Os resultados indicam que o apagamento tanto da vogal [I] quanto da vogal $[u]$ é favorecido pelo contexto seguido de consoante, como se pode observar em "Pedaço [pe'das] de unha"; "Ele ['el] não gostou”. O contexto seguido 
de pausa não apresentou efeitos estatisticamente significativos, portanto, desfavorecem o apagamento nas localidades. Ratificam-se, assim, os resultados observados em Oliveira (2012) que aponta o contexto seguido de consoante como favorecedor do apagamento.

\subsection{Resultados por sexo do informante}

Tomando por base a amostra do Beco (ROLO, 2010), o apagamento das vogais finais [I] e [U] manifesta-se de forma diferente na fala de homens e mulheres, como se pode observar na Tabela 3:

Tabela 3: Apagamento das vogais átonas finais [u] e [I], em função do sexo em Beco (em peso relativo)

\begin{tabular}{|c|c|c|c|c|c|}
\hline \multirow{3}{*}{ Localidade } & \multicolumn{2}{|c|}{ Vogal $[\mathrm{U}]$} & \multicolumn{3}{|c|}{ Vogal [I] } \\
\hline & Homem & Mulher & Homem & $\mathrm{Mu}$ & lher \\
\hline & & & $\begin{array}{ll}\text { Faixa1 } & \text { Faixa2 }\end{array}$ & Faixa1 & Faixa2 \\
\hline Весо & 0,66 & 0,32 & 0,74 & 0,08 & 0,62 \\
\hline
\end{tabular}

Fonte: Rolo (2010, p. 168, 202), com adaptações.

Em Beco, a variável sexo destaca o papel dos homens no favorecimento da regra para o apagamento da vogal $[v]$, com 0,66 de peso relativo, enquanto as mulheres a desfavorecem, com 0,32. Em relação à vogal [I], o sexo tornou-se estatisticamente significativo associado à idade. Os mais idosos do grupo, tanto homens $(0,74)$ quanto mulheres $(0,62)$ da faixa 2 , favorecem o processo de apagamento. As mulheres da faixa 1 mostraram um baixo índice de aplicação da regra $(0,08)$ e, consequentemente, um menor apagamento das vogais átonas finais. Os dados revelaram diferenças marcantes entre a linguagem de mulheres jovens e mulheres idosas. Isso pode ser explicado pelo fato de aquelas serem as mais escolarizadas do grupo e, socialmente, mais integradas. Além disso, o fato de mulheres jovens evitarem o apagamento está associado ao que diz Labov 
([1972] 2008) quando sinaliza que as mulheres empregam menos variantes estigmatizadas do que os homens e parecem mais sensíveis aos valores sociais.

Nas localidades da Bahia e de Minas Gerais, o sexo só foi selecionado associado à diatopia, como se pode observar na Tabela 4:

Tabela 4: Apagamento das vogais átonas finais [u] e [I], em função do sexo em Bom Jesus da Lapa, Macaúbas, Almenara e Itaobim (em peso relativo)

\begin{tabular}{ccccc}
\hline Localidades & \multicolumn{2}{c}{ Vogal [u] } & \multicolumn{2}{c}{ Vogal [I] } \\
\hline \multirow{2}{*}{ Itaobim } & Homem & Mulher & Homem & Mulher \\
\cline { 2 - 5 } Almenara & 0,66 & 0,55 & 0,57 & 0,56 \\
Bom Jesus da Lapa & 0,45 & 0,63 & 0,42 & 0,53 \\
Macaúbas & 0,43 & 0,41 & 0,52 & 0,55 \\
\hline
\end{tabular}

Fonte: Rolo (2016, p. 244, 268), com adaptações.

Os resultados apresentados na Tabela 4 indicam que o apagamento da vogal $[u]$ concentra-se nas localidades mineiras. Em Itaobim, o apagamento realiza-se independente do sexo do falante. $\mathrm{O}$ homem favorece a aplicação da regra de apagamento, com 0,66 de peso relativo; a mulher, com 0,55. Enquanto em Almenara, com 0,63 de peso relativo, é a mulher que o favorece. Na Bahia, homens e mulheres não alcançam representatividade significativa quanto à aplicação da regra para a vogal [u].

Com relação à vogal [I], em Itaobim, praticamente não há distinção entre homens $(0,57)$ e mulheres $(0,56)$. Os valores estão muito próximos. Em Almenara, as mulheres apresentam valor próximo à neutralidade, com 0,53 de peso relativo, e tendem a realizar mais apagamentos do que os homens. Em Bom Jesus da Lapa, observa-se pequena diferença entre homens e mulheres, encontrando-se nas mulheres $(0,55)$ pesos relativos mais elevados do que nos homens $(0,52)$, próximo à neutralidade, revelando uma tendência e não um condicionamento da regra. 
Percebe-se que o comportamento linguístico de homens e mulheres é um fator instigante. Como fator sociolinguístico, o sexo tem sido frequentemente observado nas pesquisas implementadas, mas não tem se mostrado muito relevante quando analisado isoladamente.

\subsection{Resultados por faixa etária do informante}

Com relação à faixa etária, os pesos relativos revelaram uma tendência de mudança implantada nas localidades, como se pode observar na Tabela 5:

Tabela 5: Apagamento das vogais átonas finais [u] e [I], em função da faixa etária: Beco versus localidades baianas e mineiras (em peso relativo)

\begin{tabular}{lcccc}
\hline \multicolumn{1}{c}{ Localidades } & \multicolumn{2}{c}{ Vogal [U] } & \multicolumn{2}{c}{ Vogal [I] } \\
\hline & Faixa 1 & Faixa 2 & Faixa 1 & Faixa 2 \\
\cline { 2 - 5 } Beco & 0,32 & 0,64 & - & - \\
$\begin{array}{l}\text { Localidades } \\
\text { baianas e mineiras }\end{array}$ & 0,46 & 0,53 & 0,43 & 0,56 \\
\hline Fonte: Rolo (2010, p. 169; 2016, p. 239, 264), com adaptações. &
\end{tabular}

Pode-se observar, na Tabela 5, que os falantes da faixa 2 são aqueles que realmente estão à frente do processo de apagamento nas localidades. Em Beco, os mais velhos apresentaram um alto índice de aplicação da regra para o apagamento da vogal [U], com 0,64 de peso relativo. Quanto à vogal [I], a faixa etária foi selecionada apenas associada ao sexo do informante e os resultados obtidos (Tab. 3) mostram que a faixa 2 favorece o processo de apagamento, independente do sexo.

Nas comunidades da Bahia e de Minas Gerais, a faixa 2 lidera o processo de apagamento, com 0,56 de peso relativo, para a vogal [I], e 0,53, para a vogal $[U]$. 


\subsection{Resultados por tipo de questionário}

Os resultados mostram que a variável tipo de questionário é realmente muito importante para o estudo do apagamento nas localidades. É relevante destacar que o tipo de questionário marca, com alguma precisão, o lugar do apagamento neste estudo, como se pode ver na Tabela 6:

Tabela 6: Apagamento das vogais átonas finais [U] e [I], em função do tipo de questionário em Beco (em peso relativo)

\begin{tabular}{ccccc}
\hline \multicolumn{1}{c}{ Localidades } & \multicolumn{2}{c}{ Vogal $[\mathrm{U}]$} & \multicolumn{2}{c}{ Vogal [I] } \\
\hline \multirow{3}{*}{ Beco } & Discurso & QFF & Discurso & QFF \\
\cline { 2 - 5 } & 0,58 & 0,36 & 0,95 & 0,87 \\
\hline
\end{tabular}

Fonte: Rolo (2010, p. 171, 196), com adaptações.

Em Beco, o tipo de questionário foi o fator mais importante. Em relação à vogal [v], o discurso semidirigido é o tipo de questionário que mais favorece o apagamento, com um peso relativo de 0,58, e o QFF o desfavorece, com 0,36. Quanto à vogal [I], o discurso semidirigido alcançou o mais alto índice de aplicação da regra de apagamento, com 0,95 de peso relativo. Também o QFF, onde se obtêm respostas mais monitoradas, apresentou um alto valor de apagamento, com 0,87 de aplicação da regra. Conclui-se que esteja mais associado à localidade do que ao tipo de questionário.

Tabela 7: Apagamento da vogal átona final [u], em função do tipo de questionário nas localidades baianas e mineiras (em peso relativo)

\begin{tabular}{lcc}
\hline \multicolumn{1}{c}{ Localidades } & \multicolumn{2}{c}{ Vogal $[\mathrm{U}]$} \\
\hline & Discurso & QFF \\
\cline { 2 - 3 } $\begin{array}{l}\text { Localidades baianas } \\
\text { e mineiras }\end{array}$ & 0,75 & 0,29 \\
\hline
\end{tabular}

Fonte: Rolo (2016, p. 240, 272), com adaptações.

Nas localidades da Bahia e de Minas Gerais, o discurso semidirigido revelou-se como o lugar propício para manifestação do fenômeno do 
apagamento com 0,75 de peso relativo para a vogal [u] (Tab. 7). Provavelmente isso ocorre em função do grau de espontaneidade da fala. O QFF desfavorece com um peso relativo de 0,29 .

Tabela 8: Apagamento da vogal átona final [I], em função do tipo de questionário nas localidades baianas e mineiras (em peso relativo)

\begin{tabular}{lcc}
\hline \multicolumn{1}{c}{ Localidades } & \multicolumn{2}{c}{ Vogal [I] } \\
\hline & Discurso & QFF \\
\cline { 2 - 3 } Itaobim & 0,57 & 0,54 \\
Bom Jesus da Lapa & 0,62 & 0,43 \\
Almenara & 0,46 & 0,51 \\
Macaúbas & 0,47 & 0,32 \\
\hline Fonte: Rolo (2016, p. 240, 272), com adaptações.
\end{tabular}

Quanto à vogal [I], o tipo de questionário tornou-se estatisticamente significativo associado à diatopia. Em Minas Gerais, Itaobim apresenta a mesma tendência de apagamento observada em Beco. Embora com pesos relativos mais baixos, os dois tipos de questionário favorecem o apagamento com 0,57 para discurso semidirigido e 0,54 para o QFF. Em Bom Jesus da Lapa, na Bahia, o discurso semidirigido favorece o apagamento com 0,62 de peso relativo, enquanto o QFF o desfavorece com 0,43 , o que revela certa consciência do fenômeno por parte dos informantes, evitando as formas apocopadas no discurso mais monitorado (Tab. 8).

\subsection{Resultados diatópicos}

Sabe-se que a questão diatópica é muito importante no estudo de natureza geolinguística. Embora se pesquisem também os aspectos de natureza sociolinguística, o interesse maior está na distribuição espacial das variantes, pois cada comunidade linguística pode reagir de forma distinta às mesmas variáveis 
linguísticas e sociais. Na Tabela 9, podem ser verificados os resultados, considerando todas as localidades investigadas:

Tabela 9: Apagamento das vogais átonas finais [U] e [I], em função das localidades (em

\begin{tabular}{lcc}
\multicolumn{3}{c}{ peso relativo) } \\
\hline \multicolumn{1}{c}{ Localidades } & Vogal $[\mathrm{U}]$ & Vogal $[\mathrm{I}]$ \\
\hline Beco & 0,97 & 0,94 \\
Itaobim & 0,60 & 0,55 \\
Almenara & 0,55 & 0,48 \\
Bom Jesus da Lapa & 0,41 & 0,53 \\
Macaúbas & 0,39 & 0,41
\end{tabular}

Fonte: Rolo (2010, p. 158, 197; 2016, p. 242, 265), com adaptações.

Os resultados da Tabela 9 revelam o apagamento das vogais finais como fenômeno característico do povoado de Beco, com 0,97 de peso relativo para a vogal [U] e 0,94 para a vogal [I]. O alto valor no favorecimento da regra mostra que o apagamento é uma particularidade linguística marcante na caracterização da localidade.

Em Minas Gerais, registra-se o peso relativo mais alto em Itaobim, com 0,60 de aplicação da regra para a vogal [U] e 0,55 para a vogal [I], seguindo a mesma tendência de apagamento observada em Beco. Em Almenara, a vogal [u] favorece o apagamento com 0,55 de peso relativo. Na Bahia, Bom Jesus da Lapa, com 0,53 de peso relativo, favorece o apagamento da vogal [I]. Em Macaúbas, os dados não foram significativamente representativos.

Pode-se considerar a hipótese de que, nessas localidades, observa-se o apagamento geral notado no português do Brasil, como ressalta Viaro (2005, p. 225): “Esse fenômeno parece afetar todo o Brasil. Síncopes e apócopes são muito mais frequentes no PB do que se imagina". Além disso, o fenômeno foi comprovado pela análise acústica que permitiu visualizar a presença e a ausência das vogais átonas em final de vocábulos paroxítonos. 


\section{CONSIDERAÇÕES FINAIS}

Considerando os trabalhos de Rolo $(2010,2016)$ que serviram de base para esta análise comparativa, bem como as pesquisas de estudiosos que respaldaram o fenômeno aqui apresentado, pode-se constatar que o apagamento das vogais átonas finais faz parte da realidade linguística do Brasil, não como um fenômeno generalizado, mas como um processo que se manifesta em determinadas áreas do país.

Por intermédio de uma breve análise acústica, pôde ser constatado o apagamento das vogais átonas [I] e [U] em sílaba final de vocábulos paroxítonos na fala das localidades investigadas. Tais variantes ocorreram, por exemplo, em palavras como bife ['bif] e prefeito [pre'fet] em que o sinal acústico permitiu visualizar a ausência dos segmentos vocálicos [I] e [U] no final das palavras analisadas, comprovando, assim, o apagamento.

No aspecto linguístico, os dados mostram que as consoantes pré-vocálicas que favorecem o apagamento individualmente na localidade rural do Beco (ROLO, 2010), quando agrupadas para análise quanto ao modo de articulação (ROLO, 2016), continuam favorecendo o apagamento tanto para a vogal [u], com fricativas e nasais, quanto para a vogal [I], com a predominância das oclusivas e das laterais.

Tendo em vista a perspectiva diatópica, os dados revelaram apagamento em todas as localidades pesquisadas, embora não seja a norma da maioria dos falantes. Itaobim, em Minas Gerais, revelou-se como área de apagamento, obtendo valores significativos tanto para $[\mathrm{I}](0,55)$ quanto para $[\mathrm{U}](0,60)$. Essa é a localidade que mais se aproxima do povoado de Beco onde o fenômeno é característico da localidade, com 0,97 de peso relativo, para a vogal [u], e 0,94 para a vogal [I]. 
O discurso semidirigido revelou-se como o tipo de questionário que favorece com maior força o apagamento das vogais [I] e [u] nas localidades. Provavelmente, esse favorecimento ocorre em função do grau de espontaneidade observado na fala, levando o informante a prestar menos atenção ao que é dito. É relevante destacar que, com relação à vogal [u], observam-se acentuadas diferenças nos pesos relativos entre os dois tipos de questionários em cada localidade. Assim sendo, apresentam-se evidências de que o apagamento da vogal $[u]$, tanto na Bahia quanto em Minas Gerais, apresenta algum nível de estigmatização, com falantes evitando as formas apocopadas no discurso mais monitorado. Com relação ao apagamento da vogal [I], os valores entre os tipos de questionário se aproximam, o que indica que o fenômeno é menos estigmatizado. Em Itaobim, inclusive, os dois tipos de questionário favorecem o apagamento da vogal [I], tal qual ocorre na localidade de Beco.

No que diz respeito à faixa etária, os dados revelaram que o apagamento está concentrado na faixa $2 \mathrm{em}$ todas as localidades. Esse resultado sinaliza uma mudança em curso nos padrões linguísticos das localidades com falantes mais velhos apagando mais a vogal átona final.

O estudo comparativo sobre o apagamento das vogais átonas finais [I] e [u] em localidades da Bahia e de Minas Gerais e em território português sugere que esse fenômeno em áreas brasileiras esteja relacionado ao que se observa em Portugal, onde se registrou grande redução das vogais átonas, nos mesmos contextos aqui documentados, principalmente na parte meridional do País e nas ilhas, tendo sido trazido pelos colonizadores.

\section{REFERÊNCIAS}

BERNARDO, Maria Clara Rolão. Os sons do falar micaelence. In: BERNARDO, Maria Clara Rolão; MONTENEGRO, Helena Mateus. O falar micaelense (Fonética e Léxico). Viseu: João Azevedo Editor, 2003. p. 13-125. 
BESSA, José Rogério Fontenele (coord.). Atlas Lingüístico do Ceará. Universidade Federal do Ceará. Fortaleza: Edições UFC, 2010. 2 v.

CÂMARA JR., Joaquim Mattoso. Para o estudo da fonêmica portuguesa. Rio de Janeiro: Vozes, [1953] 2008.

CÂMARA JR., J. M. Estrutura da Língua Portuguesa. 36 ed. Petrópolis: Vozes, [1970] 2004.

COMITÊ NACIONAL DO PROJETO ALiB. Atlas Lingüístico do Brasil: questionário 2001. Londrina: Editora da Universidade Estadual de Londrina, 2001.

CORRÊA, Lucas Teles. A forma clítica de pronome pessoal no dialeto mineiro: uma variante sociolinguística. 1998. 90 f. Dissertação (Mestrado) - Faculdade de Letras, Universidade Federal de Minas Gerais, Belo Horizonte, 1998.

CUNHA, Celso; CINTRA, Lindley. Nova Gramática do Português Contemporâneo. 6 ed. Rio de Janeiro: Lexikon, [1984] 2013.

GUY, Gregory Riordan; ZILLES, Ana Maria Stahl. Sociolingüística quantitativa instrumental de análise. São Paulo: Parábola Editorial, 2007.

FERREIRA, Carlota et al. Atlas Lingüístico de Sergipe. Salvador: UFBA - Instituto de Letras/Fundação Estadual de Cultura de Sergipe, 1987.

FERREIRA, Manuela Barros et al. Atlas Lingüístico-Etnográfico dos Açores - ALEAç. v. 1: A criação de gado. Centro de Lingüística da Universidade de Lisboa, Direção Regional da Cultura, Açores, Lisboa/Angra do Heroismo, 2001.

LABOV, William. Padrões sociolingüísticos. Tradução de Marcos Bagno, Maria Marta Pereira Scherre e Caroline Rodrigues Cardoso. São Paulo: Parábola, [1972] 2008.

MEDEIROS, Maria de Jesus Chichorro. A Linguagem Micaelense em alguns de seus aspectos. 1964. 552 f. Dissertação (Licenciatura) - Faculdade de Letras da Universidade de Lisboa, Lisboa, 1964.

NAVARRO, Tomás et al. Atlas Lingüístico de la Península Ibérica - ALPI. Fonética I. Madrid: Conselho Superior de Investigaciones Científicas, 1962.

NUNES, José Joaquim. Compêndio de gramática histórica portuguesa. Lisboa: Clássica Editora, [1919] 1951.

OLIVEIRA, Alan Jardel. 'Comendo o final das palavras': análise variacionista da haplologia, elisão e apócope em Itaúna-MG. 2012. 296 f. Tese (Doutorado em Linguística Teórica e Descritiva do Programa de Pós-Graduação em Estudos Linguísticos) - Faculdade de Letras, Universidade Federal de Minas Gerais, Belo Horizonte, 2012.

OLIVEIRA, Alan Jardel. A variação em itens lexicais terminados em /l/ na cidade de Itaúna/MG. 2006. 211f. Dissertação (Mestrado em Estudos Lingüísticos) - Faculdade de Letras, Universidade Federal de Minas Gerais, Belo Horizonte, 2006.

PERINI, Mário Alberto. Gramática do Português Brasileiro. São Paulo: Parábola Editorial. 2010.

RIBEIRO, José et al. Esboço de um Atlas Lingüístico de Minas Gerais. Rio de Janeiro: Fundação Casa de Rui Barbosa, 1977. 
ROBINSON, John; LAWRENCE, Helen; TAGLIAMONTE, Sali. GoldVarb 2001: a multivariate analysis application for Windows. User's manual. 2001. Disponível em: http://www.romanistik.uni-

freiburg.de/pusch/Download/variacionismo/GoldVarb2001_User_manual.pdf. Acesso em: 20 abr. 2007.

ROLO, Maria do Carmo Sá Teles de Araújo. Apócope das vogais átonas finais em duas localidades do Centro Sul Baiano: Beco e Seabra. 2010. 250 f. Dissertação (Mestrado em Letras e Linguística do Programa de Pós-Graduação em Letras e Linguística) Instituto de Letras, Universidade Federal da Bahia, Salvador, 2010.

ROLO, Maria do Carmo Sá Teles de Araújo. Apagamento das vogais átonas finais [I] e [v] em áreas da Bahia e de Minas Gerais: aspectos históricos, geossociolinguísticos e acústicos. 2016. 336 f. Tese (Doutorado em Língua e Cultura) - Instituto de Letras. Universidade Federal da Bahia, Salvador, 2016.

ROSSI, Nelson. Atlas Prévio dos Falares Baianos. Rio de Janeiro: INL, 1963.

SEGURA DA CRUZ, Maria Luísa. A Fronteira Dialectal do Barlavento do Algarve. 1987. 393 f. Dissertação (Investigador Auxiliar) - Centro de Linguística da Universidade de Lisboa, Instituto Nacional de Investigação Científica, Lisboa, 1987. v 1 - Tese; v 2 - Cartas.

VIARO, Mário Eduardo. Semelhanças entre o português brasileiro e as variedades africanas e asiáticas. In: SILVA, Luiz Antônio (org.). A língua que falamos: português: história, variação e discurso. São Paulo: Globo, 2005. p. 211-251.

VITORINO, Gabriela. Atlas Linguístico do Litoral Português: fauna e flora (introdução a dialectometria e índices). 1987. Dissertação (Investigador Auxiliar) - Centro de Linguística da Universidade de Lisboa, Instituto Nacional de Investigação Científica, Lisboa, 1987.

\section{AS AUTORAS E O PPGLinC}

\section{Maria do Carmo Sá Teles de Araújo Rolo}

Doutora em Língua e Cultura pelo Programa de Pós-Graduação em Língua e Cultura da Universidade Federal da Bahia (2016). Mestre em Letras pelo Programa de PósGraduação em Letras e Linguística da Universidade Federal da Bahia (2010). Licenciada em Letras Vernáculas pela Universidade Católica do Salvador (1989). Atuou como professora substituta na Universidade Federal da Bahia (2010-2011). É pesquisadora do Atlas Linguístico do Brasil (ALiB). Em sua abrangência de estudos, o PPGLinC teve importância relevante na pesquisa sobre o "Apagamento das vogais altas finais", desenvolvida no mestrado e ampliada no doutorado, possibilitando o registro científico de um fenômeno pouco conhecido no meio acadêmico e, com o apoio da CAPES, foi possível também estender essa investigação até Portugal, através do Doutorado Sanduíche, realizado no Centro de Linguística da Universidade de Lisboa. 


\section{Jacyra Andrade Mota}

Possui graduação em Letras pela Universidade Federal da Bahia (1961), mestrado em Letras e Linguística pela Universidade Federal da Bahia (1980) e doutorado em Letras Vernáculas pela Universidade Federal do Rio de Janeiro (2002). Professora concursada com a tese Vogais antes de acento em Ribeirópolis, Sergipe (UFBA, 1980). Co-autora do Livro das Aves (1965); do Atlas Lingüístico de Sergipe (1987); e do Atlas Linguístico do Brasil (2014). Professora Associada II da Universidade Federal da Bahia. Credenciada como Professora Permanente do Programa de Pós-Graduação em Língua e Cultura (PPGLinC) através do Programa Especial de Participação de Professores Aposentados (PROPAP). Pesquisadora e bolsista de Produtividade I-B do CNPq, atua, principalmente, nas subáreas: Sociolinguística e Dialetologia, participando dos seguintes projetos: Atlas Linguístico do Brasil (Presidente do Comitê Nacional que o coordena, desde setembro de 2018) e NURC (integrante do grupo que o implantou em 1970). O processo de concessão do Título de Professor Emérito, proposto pelo Instituto de Letras da UFBA, em junho de 2017, encontra-se em andamento.

Nota do editor:

Artigo submetido para avaliação em: 30 de setembro de 2020.

Aprovado em sistema duplo cego em: 04 de março de 2021. 